NBSIR 84-2987

\title{
Outline of CCVT Calibration Procedure, EPRI-NBS Prototype System--Supplement to EPRI Report EL-690 (Field Calibration System for CCVTs, April 1978)
}

David L. Hillhouse

U.S. DEPARTMENT OF COMMERCE

National Bureau of Standards

National Engineering Laboratory

Center for Electronics and Electrical Engineering

Electrosystems Division

Gaithersburg, MD 20899

August 1984

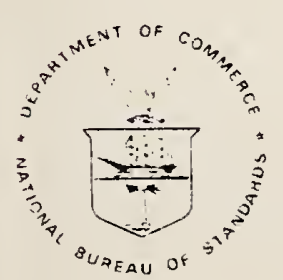

U.S. DEPARTMENT OF COMMERCE

NATINNAL BURE.AU OF STANDARDS

$\rightarrow Q C$

100

.456

84-2987

1984

c. 2 

OUTLINE OF CCVT CALIBRATION

PROCEDURE, EPRI-NBS PROTOTYPE

SYSTEM--SUPPLEMENT TO EPRI

REPORT EL-690 (FIELD CALIBRATION

SYSTEM FOR CCVTS, APRIL, 1978)

David L. Hillhouse

U.S. DEPARTMENT OF COMMERCE

National Bureau of Standards

National Engineering Laboratory

Center for Electronics and Electrical Engineering

Electrosystems Division

Gaithersburg, MD 20899

August 1984

U.S. DEPARTMENT OF COMMERCE, Malcolm Baldrige, Secretary

NATIONAL BUREAU OF STANDARDS, Emest Ambler, Director 



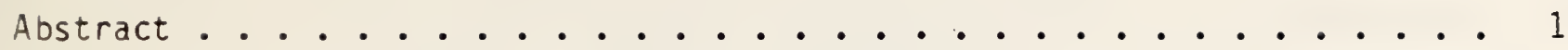

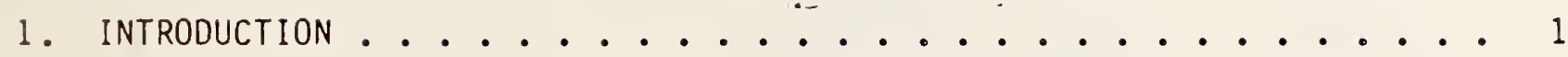

1.1 Calibration Before Going to The Field . . . . . . . . . 1

1.2 Field Calibration of Operating CCVTs........... 2

2. Detailed CalibRATION PROCEdURES. . . . . . . . . . . 2

2.1 Calibration Before Going to The Field ........... 2

2.2 Field Calibration of Operating CCVTs. ........... 4

2.3 Recalibration after Return from The Field ......... 6

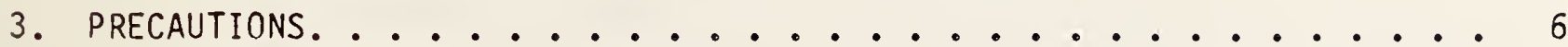

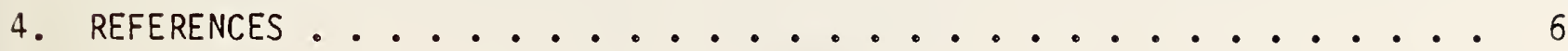




\section{LIST OF FIGURES}

Page

Figure 1. Measurement 1 -- Voltage integrity, divider module. . . . . . 7 Figure 2. Calibration of standard capacitor . . . . . . . . . . 8 Figure 3. Measurement 3 -- Calibration of standard divider. . . . . . . 9 Figure 4. Measurement 4 -- On-line calibration of CCVT. . . . . . . . .10 Figure 5. Coaxial Choke Test Circuit. . . . . . . . . . . . . . . 11 
OUTLINE OF CCVT CALIBRATION PROCEDURE, EPRI -NBS PRDTOTYPE SYSTEM--SUPPLEMENT

TO EPRI REPORT EL-690 (Field Calibration SYSTEM FOR CCVTS, Apri1, 1978)

David L. Hillhouse

ABSTRACT

This report contains, in outline form, the step-by-step procedure for use of the EPRI-NBS Prototype Field Calibration System for Coupling Capacitor Voltage Transformers (CCVTs) in the calibration of CCVTs in the substation. It was prepared for the use of EPRI (Electric Power Research Institute) personnel at Waltz Mi11, PA, where the system now resides. It is a supplement to the EPRI final report (EL-690, April, 1978) on the project in which the system was developed.

Keywords: calibration; CCVT; EPRI; high voltage; prototype; substation

\section{INTRODUCTION}

This report outlines the most important steps to be taken in the field calibration of CCVTs in the substation. It does not cover all the details of these procedures. Such details are more fully documented in the references given at the end of the report.

GENERAL NOTE: This report is a supplement to the final report [1] on the development and testing of this calibration system. Reference [1] should he studied carefully before attempting to follow the procedures out lined below.

The overall philosophy requires that the system must be calibrated at home before proceeding to the field; then recalibrated at the site. Following this, the test CCVTs are calibrated against the system, and the system calibration is repeated afterward for closure. Upon return home, the initial calibration of the system is repeated to gain assurance of overall stability.

\subsection{Calibration Before Going to The Field}

Calibration before going to the field consists of three steps, the first of which is optional, as follows:

Measurement 1 (OPTIONAL). Check of the voltage integrity of the transfer standard divider at $25 \%$ overvoltage, using the truck-mounted resonant power supply.

Measurement 2. Low-voltage calibration of the truck-mounted compressed gas standard capacitor.

Measurement 3. One-hundred-kilovolt calibration of the modular standard divider, using the truck-mounted resonant power supply.

Numbers in brackets refer to the literature references listed at the end of this report. 


\subsection{Field Calibration of Operating CCVTs}

Field calibration of operating CCVTs consists of six steps, one of which is optional:

Measurement 1. Same as Measurement 1 above.

Measurement 2. Same as Measurement 2 above.

Measurement 3. Same as Measurement 3 above.

Measurement $4 \mathrm{a}$. Check of the coaxial choke system in the signal cables.

Measurement 4. On-line calibration of the substation CCVTs.

Measurements 2 and 3 . Repeat for closure.

The procedure for recalibration of the system after return from the field is identical to that outlined in Section 1.1 for pre-calibration.

\section{DETAILED CALIBRATION PROCEDURES}

NOTE: FOR FURTHER DETAILS, SEE ESPECIALLY Sections 6-2, 7-5, and Appendix D of reference [1].

\subsection{Calibration Before Going to the Field}

Measurement 1 (OPTIONAL). Check of the voltage integrity of the modular transfer standard divider.

Step (1) Connect the circuit as shown in figure 1, making sure to short out two of the three modules (500 kV configuration).

Step (2) Turn on the current comparator bridge and detector power supplies, adjust the detector for low gain. Introduce some noise by, e.g., inserting an ungrounded "antenna" into the detector input terminals, tune the detector for maximum $60 \mathrm{~Hz}$ output.

Step (3) Turn on the $100 \mathrm{kV}$ resonant power supply, adjust input voltage to about $10 \%$ of full scale, resonate the circuit per the manufacturer's operating instructions, contained in his manual.

Step (4) Obtain a preliminary bridge balance (ratio of approximately 80:1) by alternately adjusting first the ratio and then the quadrature circuit for detector minimum. Increase detector gain as halance is approached.

Step (5) Once preliminary balance is obtained, increase voltage to $100 \mathrm{kV}$ $(120 \%$ of rated voltage per module).

Step (6) Rebalance the bridge, monitor for five minutes (time is arbitrary), record the results. Comparison with earlier data should show little shift over a period of months, and negligible five-minute drift. 
Step (7) Reduce the voltage to zero, shut off power, short a different pair of modules, repeat steps (3) through (6).

Measurement 2. Low-voltage calibration of the truck-mounted $200 \mathrm{kV}$ compressed gas standard capacitor.

Step (1) Connect the circuit as shown in figure 2.

Step (2) Turn on the bridge and detector power supplies, adjust detector for low gain. Introduce some noise, by, e.g., inserting an ungrounded "antenna" into the detector input terminals, tune the detector for maximum $60-\mathrm{Hz}$ gain.

Step (3) Turn on the $250 \mathrm{~V}$ transformer power supply, adjust to full voltage.

Step (4) Obtain a preliminary bridge balance (ratio of approximately 10:1) by alternately adjusting first the ratio and then the quadrature circuit for minimum. Increase detector gain as balance is approached.

Step (5) Obtain final bridge balance, record the results. Typical values might be:

$$
\begin{aligned}
& \text { Ratio }=1.00191 \\
& \text { Multiplier }=10 \\
& \text { Phase Angle }=0.005 \text { milliradians. }
\end{aligned}
$$

This represents the comparison of a $1000.00 \mathrm{pF}$ reference standard capacitor with the nominally $100 \mathrm{pF}$ compressed gas capacitor -value above is $1000.00 /(10 \times 1.00191)=99.809 \mathrm{pF}$.

Step (6) Reduce voltage to zero, turn off the power, secure for safety [2].

Measurement 3. One-hundred-kilovolt calibration of the modular transfer standard divider, using the truck-mounted resonant power supply.

Step (1) Connect the circuit as shown in figure 3 (500 kV configuration).

Step (2) Turn on the bridge and detector power supplies, adjust the detector for low gain. Introduce some noise, tune the detector for maximum $60-\mathrm{Hz}$ output.

Step (3) Turn on the $100 \mathrm{kV}$ resonant power supply, adjust the input voltage to about $10 \%$ of full scale, resonate: the circuit.

Step (4) Obtain a preliminary bridge balance (ratio of approximately 250:1 for $500 \mathrm{kV}$ configuration) by alternately adjusting first the ratio and then the quadrature circuit for detector minimum. Increase detector gain as balance is approached.

Step (5) When preliminary balance is obtained, increase voltage to $100 \mathrm{kV}$.

Step (6) Rebalance the bridge (there will have been a small shift due to divider voltage dependence), record the results. Typical values might be: 
Ratio $=0.49775$

Multiplier $=500$

Phase angle $=2.60$ milliradians.

As the mathematics in [1] will show, the standard divider (SD) ratio is obtained from a combination of the Measurement 2 and Measurement 3 values, as follows:

SD Ratio $=(10 \times 1.00191)(500 \times 0.49775)=2493.50$.

SD Phase Angle $=2.60+0.005=2.65$ milliradians .

Step (7) Reduce the voltage to zero, turn off the power, secure for safety [2].

\subsection{Field Calibration of Operating CCVTs}

The first three measurements below are identical to those in Section 2.1.

Measurement 1 (OPTIONAL). Check of the voltage integrity of the modular transfer standard divider.

Measurement 2. Low-voltage calibration of the $200 \mathrm{kV}$ truck-mounted compressed gas standard capacitor.

Measurement 3. One-hundred-kilovolt calibration of the modular transfer standard divider, using the truck-mounted resonant power supply.

Measurement $4 \mathrm{a}$. Check of the coaxial choke system (fig. 5)

NOTE: A discussion of the theory of Measurement $4 a$ will be found in Appendix 6 of reference [3]. The choke test circuit is located on top of the bridge. It performs, by means of switches and a slightly different technique, the test shown in figure 18, Appendix A-6, reference [3]. The voltages of concern are $V$, between grounds $G 1$ and $G 2$, and $V_{92}$, between grounds $G 2$ and $G 3$, figure 16 of the same reference. These voltages must be cancelled in order to avoid significant error in Measurement 4.

Step (1) Connect the circuit for CCVT calibration, as shown in figure 4, EXCEPT DO NOT MAKE the plugboard connections $1-9$ and 2-7, as called for on page $0-16$ of reference [1], shown also as open circuits on figure 5 of this report.

Step (2) With the center conductors of the standard divider (SD) and test piece (TP) signal cables shorted to shield at the divider and in the control house, respectively,

(a) Plug a DVM into the choke test circuit output.

(b) Select the SD choke with the standard divider position of the choke selector switch.

(c) With the function selector switch in the choke selector position, readthe "choke-in" voltage on the DVM (should be no more than a few millivolts if choke is working correctly). 
(d) With the function selector switch in the choke monitor position, read the "choke-out" voltage by the same means (may be 0.1 to 0.5 volts in a typical substation).

(e) Select the TP choke with the test piece position of the choke selector switch, repeat the above procedure.

(f) Place the function selector switch in position 4 .

NOTE: The choke out position of the function selector switch can also be used to monitor the full line voltage (approximately 120 volts) when the system is in operation.

Measurement 4. On-line calibration of the substation CCVTS.

Step (1) Connect the circuit as shown in figure 4, carefully following the safety procedures out lined in Sections 3 and 4 of reference [2].

Step (2) Turn on the bridge and detector power supplies, adjust the detector for low gain. Introduce some noise, tune the detector for maximum $60-\mathrm{Hz}$ output.

Step (3) Instruct the control house to connect and identify the low side of a test piece (CCVT).

Step (4) Balance the bridge (ratio of approximately $1: 1$ for a $500 \mathrm{kV}$, three-module divider) by alternately adjusting first the ratio and then the quadrature circuit for detector minimum. Increase detector gain as balance is approached.

Step (5) Record the results. Typical values may be:

$$
\begin{aligned}
& \text { Ratio }=0.98989 \\
& \text { Multiplier }=1.0 \\
& \text { Phase Angle }=0.44 \text { milliradians. }
\end{aligned}
$$

The CCVT ratio is obtained by combining the data from Measurements 2,3 , and 4 . Using the values from Measurement 2, Step (5) and Measurement 3, Step (6):

$$
\begin{aligned}
& \text { CCVT Ratio }=(10 \times 1.00191) \times(500 \times 0.49775) \\
&(1.0 \times 0.98989)=(10 \times 500 \times 1.0) \times \\
&(1.00191 \times 0.49775 \times 0.98989)=2468.29 . \\
& \text { CCVT Phase Angle }=2.60+0.005+0.44= \\
& 3.09 \text { milliradians. }
\end{aligned}
$$

Step (6) Switch control house connections to another CCVT, repeat Steps (3) through (5) above.

Step (7) Disconnect from the high voltage bus, carefully following Section 5 of reference [2]. Repeat Measurements $4 a$ and 4 for another phase. 
Measurement 2 and 3 . Repeat for closure.

At the end of each day, and at the end of the test, the divider is recalibrated, in order to correct for any drift in its values (primarily due to self-heating).

\subsection{Recalibration after Return from the Field}

Repeat the calibration outlined in Section 2.1 (Calibration Before Going to the Field).

\section{PRECAUTIONS}

Be sure to perform the ground voltage checks called for in for in Section 2.2 , Measurement $4 a$, at least once for every change of phases.

Use the same standard divider cable for all measurements. This cable forms part of the divider low-side capacitance, so that it changes the value of a 2500:1 ratio $(500 \mathrm{kV})$ by approximately $0.01 \%$ per meter of cable length.

\section{REFERENCES}

[1] Hilhouse, D. L., Petersons, 0., and Sze, W. C., A Prototype Field Calibration System for Coupling Capacitor Voltage Transformers (CCVTs), EPRI Final Report No. EL-690 (Apri1 1978).

[2] Hillhouse, D. L., Guide for Safe Operating Procedures...During the Field Calibration of CCVTs, NBSIR 81-2192, (Feb. 1981).

[3] Hillhouse, D. L., Petersons, 0., and Sze, W. C., A Simplified System for Calibration of CCVTs in the Substation, NBS Technical Note 1155, (May 1982).

[4] Hillhouse, D. L., Petersons, 0., and Sze, W. C., A Prototype System for On-Site Calibration of Coupling Capacitor Voltage Transformers (CCVTs), IEEE Transactions on Power Apparatus and Systems, Vol. PAS-98, (May/June 1979), 1026-1036. 


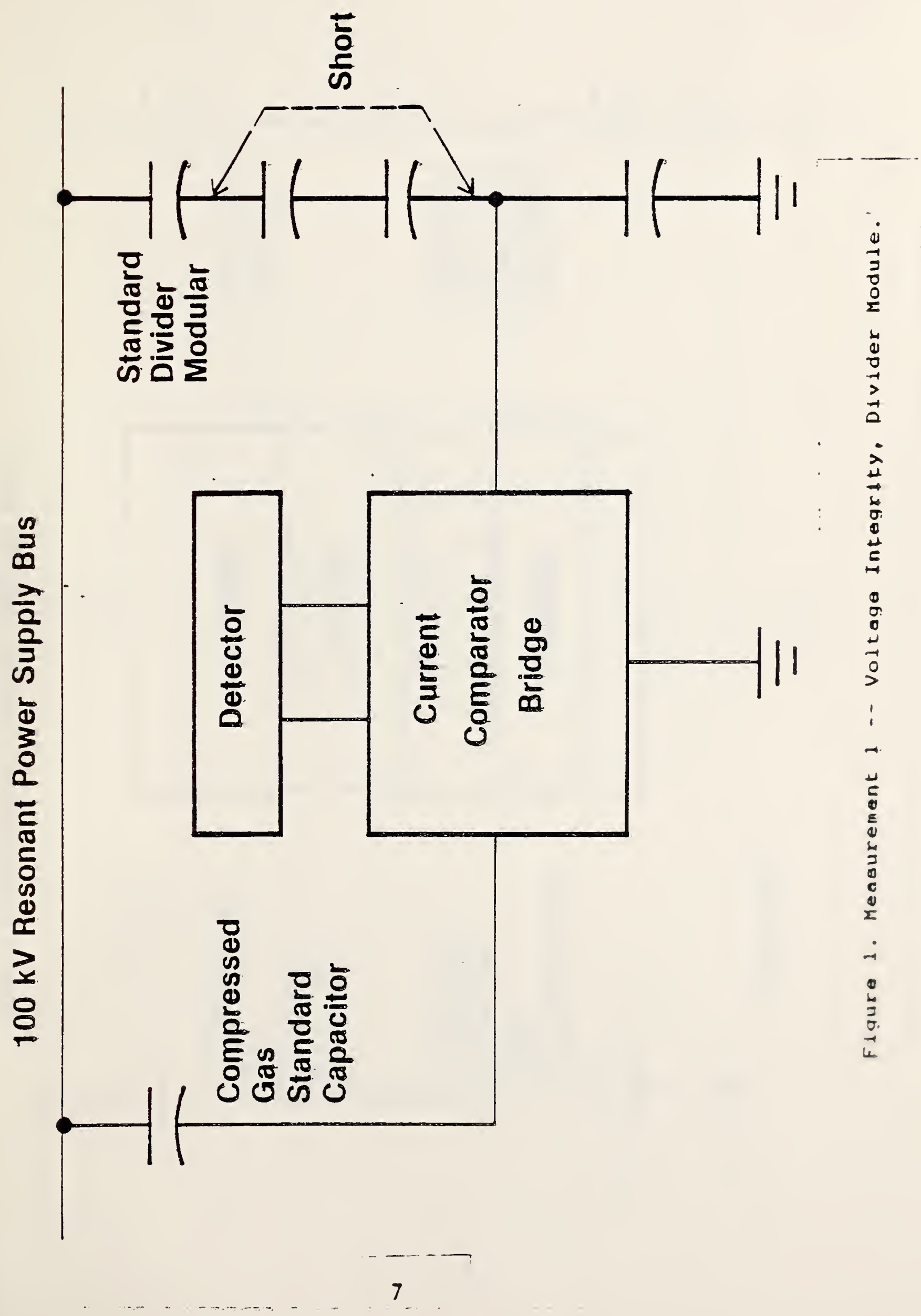




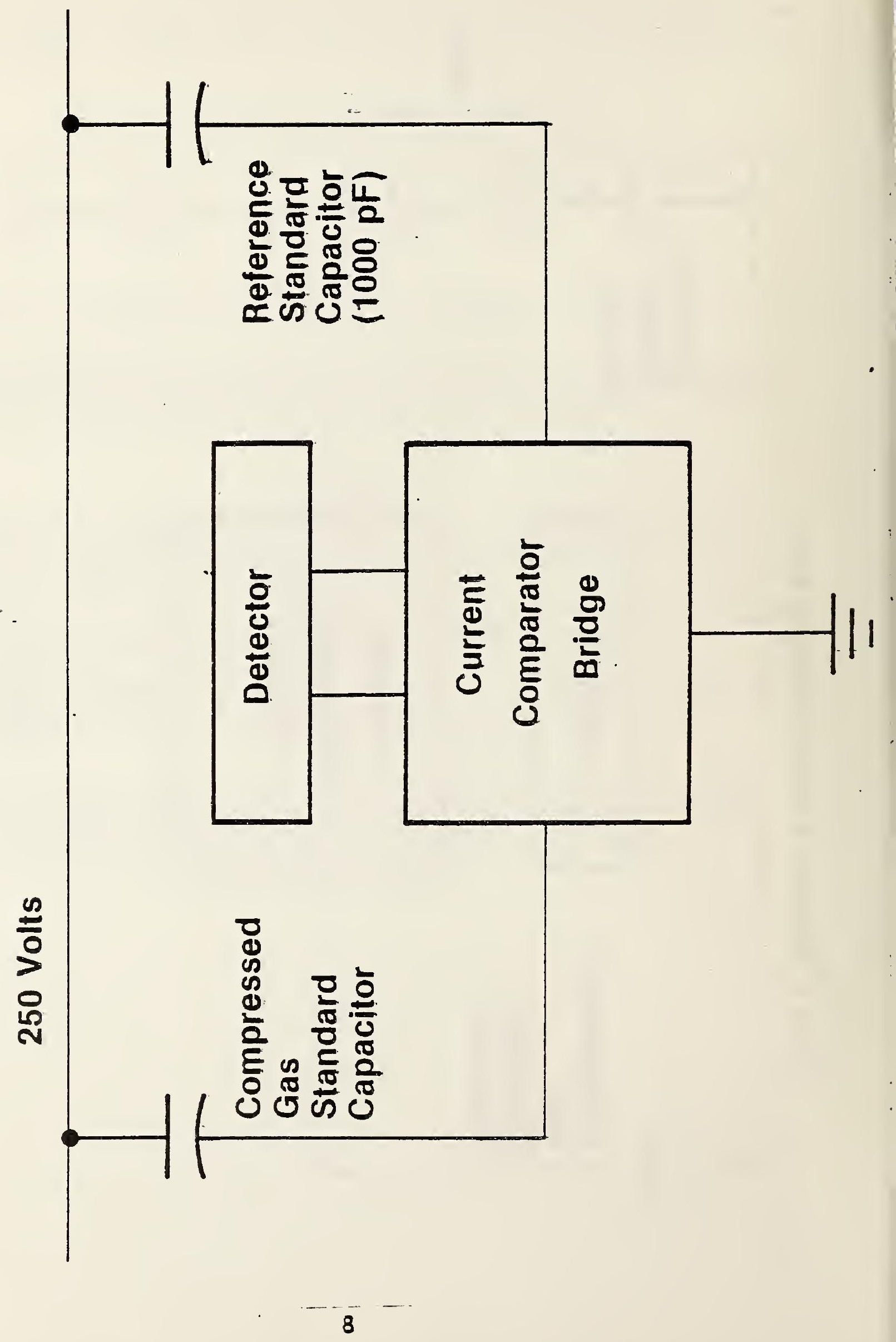




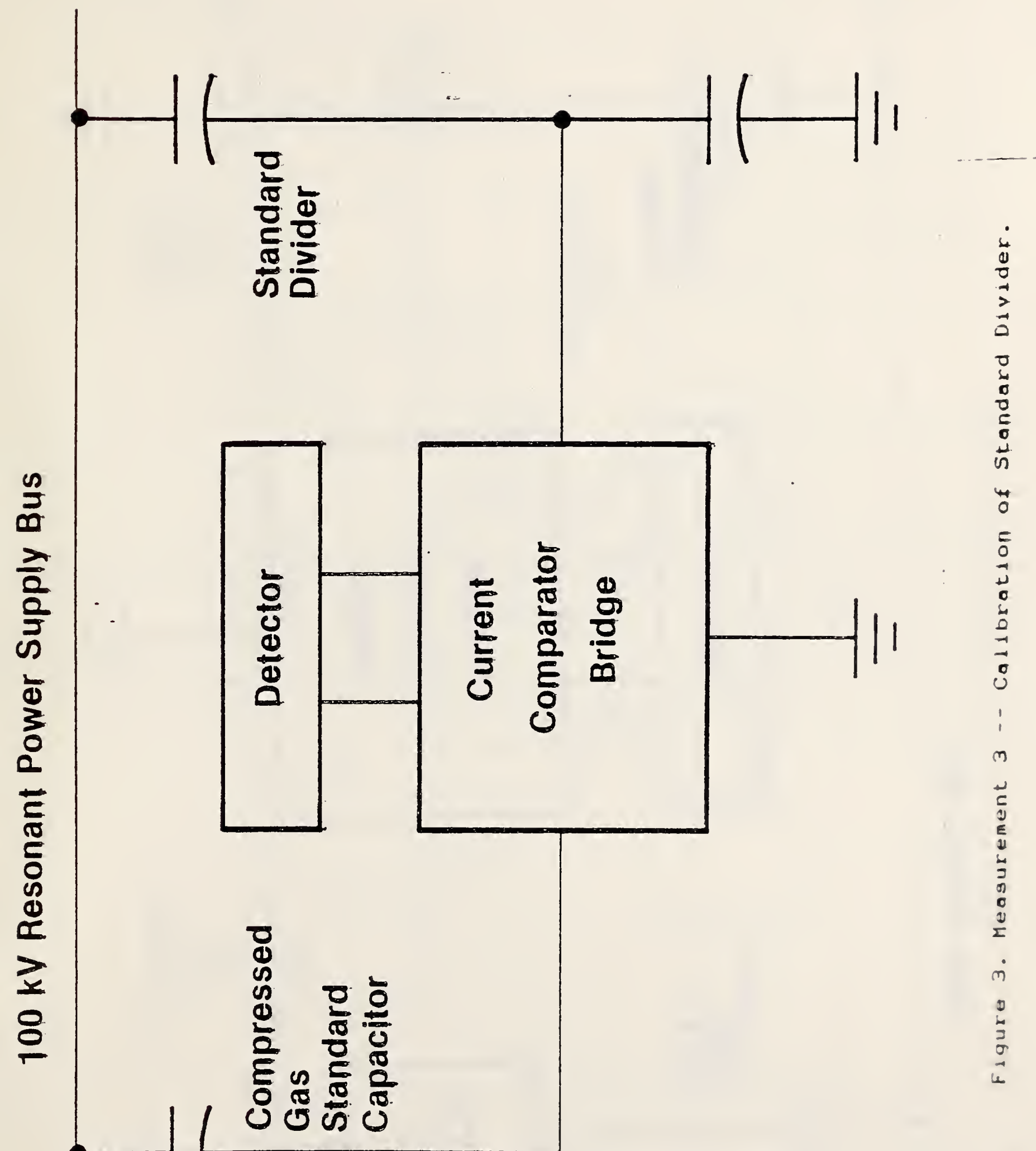




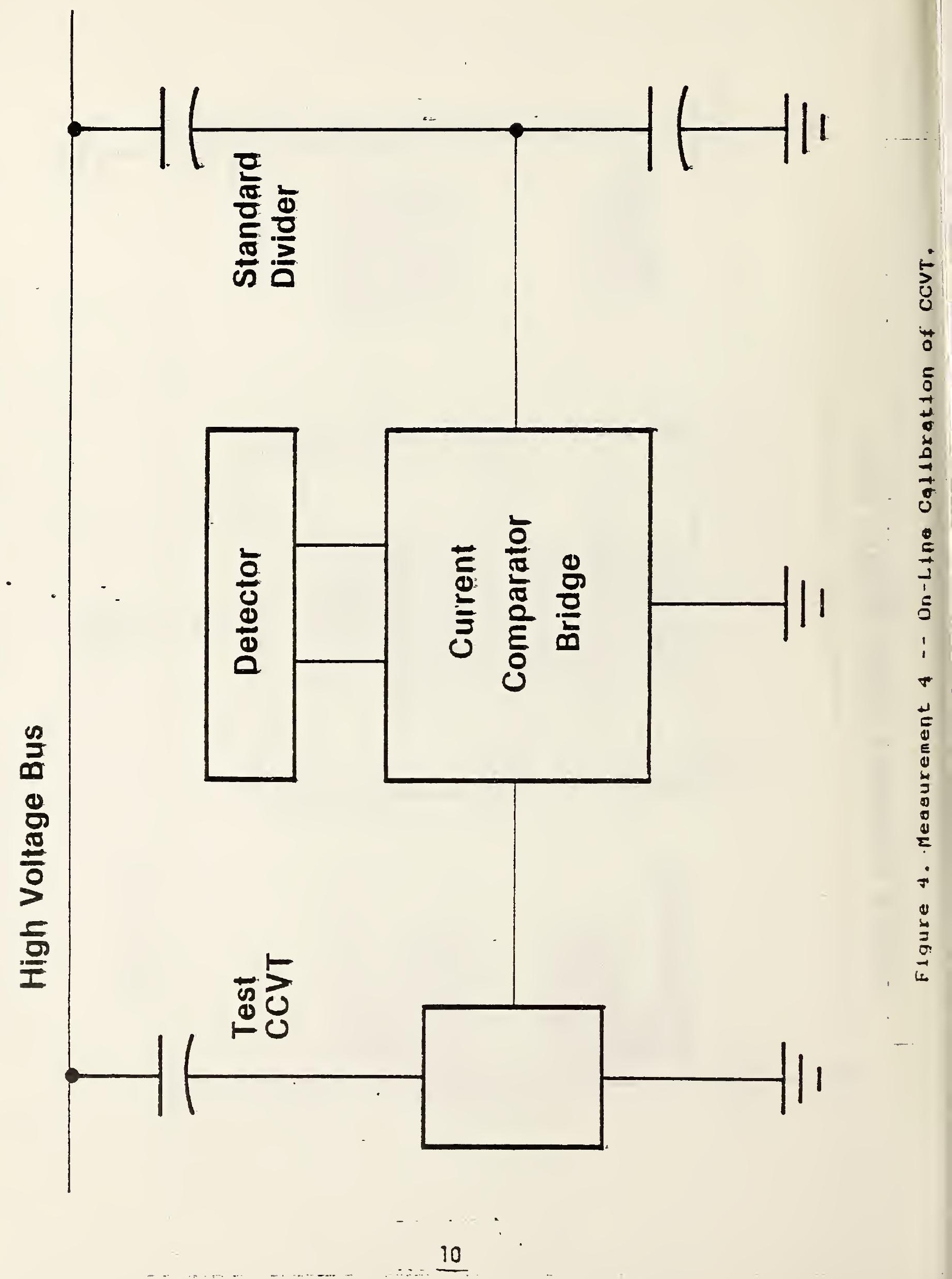




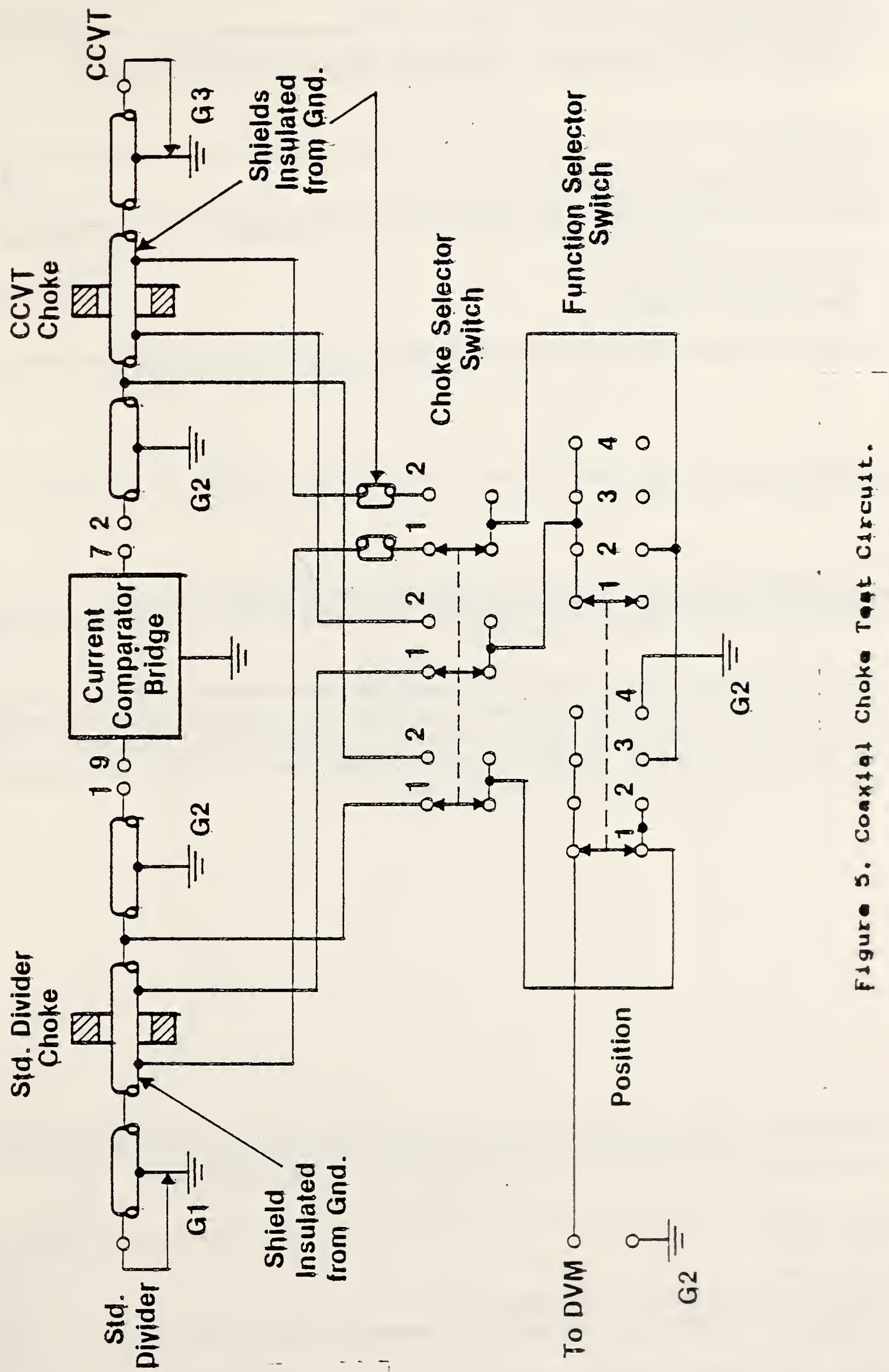


NBS-114N (NEV. 200$)$

U.s. DEPT. of COMH

BIBLIOGRAPHIC DATA

SHEET (See in stucions)

1. PUBLICATION OR REPORTNO.

NBSIR $34-2987$

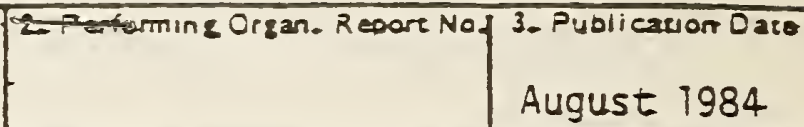

4-TITLE ANO SUBTITLE

OUTLINE OF CCVT CALIBRATION PROCEDURE, EPRI-NBS PROTOTYPE SYSTEM--SUPPLEMENT TO

EPRI REPORT EL-690 (Field Calibration System for CCVTs, April 1978)

5. AUTHOR(S)

David L. HiTThouse, Physictist

6. PERFORMING ORGANIZATION (If joine or other than NBS. see inseructions)

MATIONAL BUREAL OF STANDARDS

DEPARTMEMT OF COMMERCE

WASHINGTON, O.C. 20234

3. SPCNSORING ORGANIZATION NAME ANO COMPLETE ADDRESS (SUECL, Gity, StORE, ZIP)

T. Contrace/Grane No.

8. Type of Report \& Period Covered

10- SUPPLEMENTARY NOTES

Document deseribes, a computer program. SF-185. FIPS Sofware Summary, is actached.

1. ABSTRACT (A 200-word or less foctual summan of most significont informotion. If document includes a significons bibliogrophy or literoturo survey. mencion it here)

This report contains, in outi ine form, the step-by-step procedure for use of the EPRI-NBS Prototype Field Calibration Systen for Coupling Capacitor Voltage

Transformers (CCVTs) in the calibration of CCVTs in the substation. It was prepared for the use of EPRI (Electric-Power Research Institute) personnel at Waltz Mill, PA, where the systen now resides.

12. KEY WORDS (Six to iwelvo encries: alpnobetical order: capitalize only proper names: and separate key words by semicolons) calibration; CCVT; ERRI; high voltage; prototype; substation

\section{AVAILABILITY}

X Untimiced

$\square$ For Official Olsuribution. Do Nor Release to NTIS Order From Suderincendent of Cocumenss. U.S. Govemment Printing Office. Washington. O.C.

X Order From Nacional Technical Information Service (NTIS). Joringfield, VA. 2216i
14. NO. OF

PRINTED PAGES

16

15. Price

$\$ 7.00$ 
-

$-$ 
